( 2022 , The Authors. Published by Elsevier Inc. and Fass Inc. on behalf of the American Dairy Science Association ${ }^{\circledR}$. This is an open access article under the CC BY license (http://creativecommons.org/licenses/by/4.0/).

\title{
Farmers' preferences for adopting on-farm concentration of raw milk: Results from a discrete choice experiment in Germany
}

\author{
Corinna Weissgerber ${ }^{1}(1)$ and Sebastian Hess ${ }^{2 *}$ () \\ ${ }^{1}$ Department of Bioprocess Engineering, University of Applied Sciences and Arts Hannover, 30453 Hannover, Germany \\ ${ }^{2}$ Department of Agricultural Markets, University of Hohenheim, 70593 Stuttgart, Germany
}

\begin{abstract}
Milk concentrates are used in the manufacturing of dairy products such as yogurt and cheese or are processed into milk powder. Processes for the nonthermal separation of water and valuable milk ingredients are becoming increasingly widespread at farm level. The technical barriers to using farm-manufactured milk concentrate in dairies are minimal, hence the suspicion that the practice of on-farm raw milk concentration is still fairly uncommon for economic reasons. This study, therefore, set out to investigate farmers' potential willingness to adopt a raw milk concentration plant. The empirical analysis was based on discrete choice experiments with 75 German dairy farmers to identify preferences and the possible adoption of on-farm raw milk concentration. The results showed that, in particular, farmers who deemed the current milk price to be insufficient viewed on-farm concentration using membrane technology as an option for diversifying their milk sales. We found no indication that adoption would be impeded by a lack of trustworthy information on milk processing technologies or capital.
\end{abstract}

Key words: discrete choice experiment, on-farm raw milk concentration, random parameter logit model, latent class analysis

\section{INTRODUCTION}

In recent decades, dairy farming in Germany has experienced sweeping technical and structural changes within the production process. The use of an automatic milking system, for example, is one of the labor-saving innovations in dairy farming that allows farmers to steadily increase their herd sizes. Meanwhile, the total number of dairy farms has declined (Federal Statistical

Received March 26, 2021.

Accepted December 11, 2021.

*Corresponding author: s.hess@uni-hohenheim.de
Office, 2021). Under the European quota regimen, milk production remained largely stable. Between 2000 and 2013, the European Commission endeavored to lead the dairy market toward deregulation by gradually increasing quota volumes, among other measures, and by ultimately abolishing the milk quota in 2015. Even before that, European dairy farmers had been confronted with increased milk price volatility. In addition, raw milk prices have continued to remain highly volatile since about 2007 (European Commission, 2021).

These developments led to considerable fluctuations in revenue, which, in turn, affects both the dairy farmers' farm management and the families' income security (Hoehl and Hess, 2021). Thus, strategies to cope with increasing market-based risk are becoming ever more crucial for farmers. Several risk reduction strategies may be used, such as hedging, insurance, contracting, or the use of risk-reducing inputs (Just and Pope, 2003). In addition, diversification can be a strategy to minimize the risk to farm income (Wimmer and Sauer, 2020). For example, broadening of the existing product range can also contribute to risk diversification. For instance, dairy farmers might sell their milk through on-farm vending machines (filling stations) or process parts of their farms' milk output as drinking milk, yogurt, or cheese, by establishing small-scale dairies for direct marketing (Becker et al., 2007).

The concentration of raw milk on the farm by means of reverse osmosis (RO) could be another alternative. This would lead to the manufacture of a refined product that can be sold directly to milk processing companies. However, the conditions and farmers' willingness to adopt on-farm concentration have not yet been studied in any detail.

\section{RO for Raw Milk Concentration}

Reverse osmosis is a membrane separation technique that uses a semipermeable membrane to concentrate aqueous solutions. In the case of raw milk, RO can be used to increase DM content by a factor of 2 from approximately 13 to $26 \%$. The separation process is based 
on the diffusion of particles through the membrane, which primarily retains dissolved substances such as salts and lactose. Reverse osmosis allows solutions or milk to be concentrated purely mechanically with the help of pump energy. Compared with competing processes such as evaporation and freeze concentration, RO is the cheapest in terms of specific energy consumption. According to Stabile (1983), the concentration of skim milk by $\mathrm{RO}$ has a primary energy requirement of $27 \mathrm{~kJ} /$ $\mathrm{kg}$ of $\mathrm{H}_{2} \mathrm{O}$, compared with $200 \mathrm{~kJ} / \mathrm{kg}$ of $\mathrm{H}_{2} \mathrm{O}$ for evaporation (Henning et al., 2006; Kessler, 2006; Ramírez et al., 2006). Furthermore, in contrast to evaporation, there is no thermal load due to lower process temperatures during RO, which leads to higher food quality (Kessler, 2006).

German dairies received 31.8 million tonnes of raw milk in 2019, of which about $19 \%$ was then concentrated and processed into dry milk products (Federal Office for Agriculture and Food, 2020). In addition to milk powder production (Schuck, 2011), concentrated milk can be used as a component of other dairy products, such as yogurt (Robinson, 2011) and cheese (Chamberland et al., 2020; Lauzin et al., 2020). Reverse osmosis decreases water content and improves quality. This implies that RO technology is also potentially beneficial in terms of ecological sustainability: transportation of on-farm concentrated milk to dairies and milk processing companies reduces the weight and the need for cooling compared with raw milk. This is assumed to lead to a reduction in transport-related $\mathrm{CO}_{2}$ emissions. Additionally, the water generated as a side stream from the filtration process could be reused on the farm - for example, to clean the milking parlor (Vourch et al., 2008).

Slack et al. (1982b) and Garcia III and Medina (1988) pioneered research work on the use of membrane separation on dairy farms in the 1980s. However, their studies approached the topic solely from a technological point of view. The comprehensive quality parameters of milk processed on farms by membrane separation were investigated by de Boer and Nooy (1980) and Zall (1984). Sørensen et al. (2016) published more recent studies on the chemical quality of the concentrates. Because the concentrate produced by RO can subsequently be processed in a conventional dairy processing plant, Sørensen et al. (2017, 2019) investigated whole milk powder and rennet coagulation of cheese produced from on-farm concentrated milk.

In summary, the available literature on technological aspects of on-farm membrane separation does not show evidence of technical limitations. Consequently, technical constraints do not explain why on-farm concentration techniques are not used in practice.

\section{Economics of On-Farm Concentration}

Slack et al. (1982a) carried out an economic analysis of raw milk ultrafiltration for US farmers. They looked at the annual costs incurred as a function of 4 different herd sizes (50, 100, 500, or 1,000 animals) and 3 model situations (no concentration, double concentration, and triple concentration). The results showed that, under the current conditions, the concentration system could be run economically with a herd size of 100 animals or more.

Cox and Langdon (1985) investigated one way of using RO to reduce milk transport cost osmosis. They undertook an economic analysis of the operation of an $\mathrm{RO}$ plant seeking to reduce transportation costs between collection depots or regional dairies and urban centers in Australia. The analysis showed that the internal rate of return is higher than a minimum interest rate of $15 \%$. The investment is, therefore, deemed to be beneficial. The internal rate of return is heavily influenced by the applied transportation costs, the share of transportation cost savings due to concentration, the annual processing volume, and the investment volume. Factors such as energy costs, membrane lifetime, membrane replacement costs, and personnel costs only minimally influence the internal rate of return.

In other economic studies Winchell and Hammond (1984), Fleming and Hamm (1988), Schiek and Babb (1989), and Buningh (1990) analyzed the use of membrane filtration to reduce transport costs between central milk collection stations and transport to dairies in the United States and Canada. However, these results are not transferable to the European and German dairy industries and would also have to be revised with regard to technological developments in membrane filtration systems. Furthermore, the previously mentioned reflections refer to a cost basis. Possible adaptation barriers of the farmers have not been considered.

\section{Conceptual Framework}

The determinants of farmers' willingness to adopt certain technologies have been an important subject of agricultural research (Feder et al., 1985; Nowak, 1987; Feder and Umali, 1993). The innovation-diffusion model of Rogers (1983) states that adoption of new technologies is determined by the complexity and compatibility of the technology, potential users' socioeconomic status, knowledge and perception of the technology, and communication channels (Sunding and Zilberman, 2001). Hence, it is important to keep this complexity in mind when assessing the willingness and ability of farmers to adopt on-farm concentration of raw milk. 
In adoption studies, minimal attention is typically paid to technology characteristics (Adesina and Zinnah, 1993). However, there is usually some analysis of the degree to which the characteristics of a technology, such as complexity, risk, and investment characteristics may significantly influence adoption decisions. Some studies indicate that the personal attitudes of farm owners significantly affect adoption decisions (Adesina and Baidu-Forson, 1995; Adrian et al., 2005). Nevertheless, empirical studies that look at the adoption of innovative technologies in the field of agriculture for on-farm concentration of raw milk are still lacking.

Trujillo-Barrera et al. (2016) examined the reasons why hog producers in the Netherlands adopt sustainable practices. They found that higher risk perception was associated with lower acceptance, especially of the financial risk. Aspects such as expected personal and social rewards did not affect acceptance.

Schreiner and Latacz-Lohmann (2015) investigated the relevant factors that lead to farmers switching from conventional to genetically modified organism (GMO)free feeding. Variables such as feed monitoring and free advice lead to a higher probability of adaptation. As soon as extrinsic factors, such as requirements by dairies and restriction of autonomy, come into play, this leads to a lower adaptation probability. Other significant variables that influence selection probability included age, education, and the procurement method for GMO-free feed. Furthermore, Danne and Musshoff (2017) showed that factors such as milk yield and herd size influence willingness to implement grazing management.

Gebrezgabher et al. (2015) showed in their study that age, level of education, and farm size are important variables for predicting the probability of adoption of a manure separation technology. In addition, the attitude of farmers toward different separation technologies has a significant effect on the likelihood of adoption.

Van De Gucht et al. (2017a) investigated how the preference for cattle lameness detection systems depends on the specific attributes of this technology. The results showed that, after being informed of the consequences of lameness, farmers prefer automated systems to visual inspection. In another study, Van De Gucht et al. (2017b) used a discrete choice experiment (DCE) to calculate willingness to pay (WTP) for the different attributes in lameness detection technologies. The farmers were willing to pay $€ 2.57$ for each percent of positively diagnosed lame cows.

Thus, DCE have been used previously to determine dairy farmers' preferences for the adoption of certain technologies. The derived WTP measures appear to provide plausible money metric measures in this respect. Therefore, this paper used a DCE to investigate
German dairy farmers' potential willingness to adopt a membrane-based processing technology for on-farm raw milk concentration. In particular, we aimed (1) to investigate how the design of the membrane filtration plant - for example, the degree of automation - affects the farmers' decisions; (2) to identify which of the dairy farmers' personal determinants affect the decision; (3) to explore the heterogeneity of preferences among farmers; and (4) to draw conclusions for a configuration of on-farm concentration in Germany.

\section{MATERIALS AND METHODS}

All research complied with the requirements of the University of Applied Sciences and Arts Hanover (Hannover, Germany) for research that involves humans, as well as the guidelines for safeguarding good research practice (Deutsche Forschungsgemeinschaft, 2019). Approval from the Commission for Transparency and Ethics in Research at the University of Applied Sciences and Arts Hannover was not required.

\section{Data Collection}

The empirical analysis in this study was based on a paper questionnaire. The data were collected at one of the world's largest international fairs for animal production technology in Hanover, Germany (EuroTier 2018). This approach was chosen because confidential restrictions pertaining to dairy farm address data make it difficult to access random samples of dairy farmers in a large geographical area.

To ensure the comprehensibility of the choice task and the other questions, the questionnaire was pretested with a sample of 7 dairy farmers before conducting the final survey at the fair. During the fair, 5 contact persons were spread over the exhibition halls of relevance for dairy farms. Participants were asked in advance whether they were dairy farmers and were informed about the motivation and purpose of the study. If they had any queries, they could contact the available contact person at any time. Participants did not receive a reward for participating in the study. To ensure that study participants understood the technology on offer, we provided a schematic figure of a filtration system showing incoming and outgoing product streams, approximate space requirements, and additional information about the potential reuse of the water produced during filtration.

The questionnaire consisted of 4 parts. The first part explained the principle of membrane filtration technology for on-farm use and provided an outline of the experiment. This was followed by the DCE for the appropriate on-farm concentration of raw milk. The 
second part of the questionnaire contained general questions about the participant's farm, personal attitudes toward new technologies, and general risk preferences. The third part of the questionnaire contained further questions on milk production and delivery. Finally, the surveyed farmers answered sociodemographic questions about themselves (part 4). The questionnaire is available on request from the authors.

\section{Discrete Choice Experiment}

A DCE was used to determine farmers' preferences for an on-farm raw milk concentration module. These experiments constitute a method for elucidating stated preferences. They are widely used in agriculture to examine choice behavior in hypothetical situations.

The DCE method is based on the random utility theory of Luce (1959) and McFadden (1974). Assuming utility maximization, each subject chooses the alternative that offers the highest value. A farmer will only choose on-farm concentration of raw milk if the perceived benefit exceeds the benefit of the status quo alternative.

To examine the preferences of German farmers for adopting on-farm concentration of raw milk, the use of a DCE was advisable because no data currently exist on real decisions for such plants. Therefore, an experimental design was required to determine preferences for certain attributes.

\section{Attributes and Levels in the Discrete Choice Experiment}

The DCE used in this study presented the following decision situation to the farmers taking part in the survey: farmers had to choose 1 of 2 alternatives of on-farm raw milk concentration, or they could decide not to adopt any of these alternatives (opt-out). An opt-out option was included because a forced choice can lead to inaccuracy and inconsistency in the decision theory, and participation in raw milk concentration is voluntary.

In each decision-making situation, the participating milk producers chose between 2 different alternatives, neutrally labeled "alternative 1" and "alternative 2." The following 5 attributes were used to describe the alternatives: plant operation, marketing option, investment type, concentrated milk amount, and profit. These attributes and their levels were selected based on the premises of relevance and complexity of the experiment. This was done by considering the existing literature (see following sections), conducting expert interviews, and analyzing existing small-scale plants for milk membrane filtration. Table 1 gives all the attributes and the full range of attribute levels used in the choice experiment.

Plant Operation. Increased use of new technologies can shorten working hours and increase flexibility on dairy farms. However, various technologies to increase efficiency encounter low acceptance. This may be due to the uncertainty and associated risk of the technologies or technology combinations (Gargiulo et al., 2018; Rutten et al., 2018; Dela Rue et al., 2020). Consequently, 3 different operating membrane separation systems were listed that reflect an effect on labor and the complexity of operation. First, the entire apparatus and its periphery, such as pumps and valves, can be operated entirely via a programmed control system. Second, the entire apparatus and its periphery are operated via a central control, with target values set by the opera-

Table 1. Attributes and levels in the choice experiment

\begin{tabular}{ll}
\hline Attribute & Possible level \\
\hline Plant operation & (1) Fully automated \\
& (2) Semi-automated \\
(3) Manual control & (1) Processor to whom the farmer currently delivers \\
Marketing option & (2) Alternative supra-regional processor of concentrate \\
& (3) Spot market for milk concentrates \\
Investment type & (1) Ownership with a service contract \\
& (2) Ownership without a service contract \\
& (3) Leasing with a service contract \\
Share of own milk to be sold as concentrate & (4) Leasing without a service contract \\
& (1) Whole milk volume as concentrate \\
& (3) $50 \%$ delivery as raw milk and $30 \%$ as concentrate \\
Profit (euro cents $/ \mathrm{kg}$ ) of processed raw milk & (4) $30 \%$ delivery as raw milk and $50 \%$ as concentrate \\
& (1) 0.50 \\
& (2) 1.00 \\
& (3) 1.50 \\
\hline
\end{tabular}


tor. Third, all system elements are switched on and set manually, with the values obtained shown on a display. Against this backdrop, the "plant operation" attribute had the following 3 specifications: (1) fully automated, (2) semi-automated, or (3) manual control.

Marketing Option. German dairy farmers usually have long-term milk supply contracts with an obligation to deliver exclusively to one processor (most of which are cooperatives), but without fixed quantities. Most farmers learn their monthly milk "price" only after delivering their milk to the dairy (Petersen and Hess, 2018). Concentrating the milk could, therefore, open up additional marketing options, as new customers and negotiation forms might become possible.

The spot or bulk market offers another opportunity for selling milk. This is a market where raw milk, various concentrates, and cream are traded between dairies, milk dealers, and the processing industry. However, in principle, farmers could also enter this market as suppliers of milk concentrate. Depending on the market situation, the achievable prices change daily and can be significantly above or below the dairies' farm gate payout prices (German Federal Cartel Office, 2009). The marketing option attribute was thus designed with 3 levels derived from existing options in Germany: (1) a processor to whom the farmer currently delivers, (2) an alternative supra-regional processor of concentrate, or (3) a spot market for milk concentrates.

Investment Type. In addition to financing investment in farm technology through equity or a bank loan, there is also the option of leasing machines, systems, and equipment. This means that equity and collateral can be reserved for other investments. Furthermore, leasing contracts have the advantage that the machines are state-of-the-art, as leasing contracts are signed only for a defined period of time. However, leasing imposes new machinery, and leasing is often more expensive than financing through a loan (Landwirtschaftliche Rentenbank, 2020). For operators of industrial equipment, service contracts offer security at a fixed price, as the service providers bear the costs of maintaining and repairing their customers' equipment after (unexpected) failures (Schmitz et al., 2016). Consequently, the analysis of how farmers would purchase an on-farm concentration plant was based on the following levels for the "investment type" attribute: (1) ownership with a service contract, (2) ownership without a service contract, (3) leasing with a service contract, or (4) leasing without a service contract.

Share of Own Milk to be Sold as Concentrated Milk. Because a mix of different marketing forms is often used for agricultural products (Kuhnert and Wirthgen, 1996), the participants in the study were also presented with the option of a mix of (1) the entire milk volume as concentrate, (2) $70 \%$ delivery as raw milk and $30 \%$ as concentrate, (3) $50 \%$ delivery as raw milk and $50 \%$ as concentrate, or (4) $30 \%$ delivery as raw milk and $70 \%$ as concentrate.

Profit. A monetary variable, such as a compensation payment or product price, is required in a DCE to calculate the WTP. In our case, this could be either the investment volume for a raw milk filtration device with corresponding peripherals or the profit generated by such an investment. However, the monetary amount will depend on the size of the device or its processing volume: a farm with a larger milk volume may need a different plant than a farm with a lower milk volume. In addition, variables such as operating time and the amount of labor required for different levels of automation influence the cost of producing raw milk concentrate. Consideration of these factors leads to a highly farm-specific situation that has to be considered to quantify the actual investment volume.

Consequently, we implicitly factored this into the cost calculation. All these factors are, therefore, deemed to be included in the hypothetical profit, as proposed in the DCE. This hypothetical profit in euro cents, hereafter "cents," for processed raw milk was $0.5,1.0$, or 1.5 cents/kg in the DCE.

Previous studies conducting DCE with German dairy farmers have selected a similar price range. Schreiner and Hess (2017) and Schreiner and Latacz-Lohmann (2015) chose a range of price premiums of 0.50 to 1.00 to 1.50 to 2.00 cents $/ \mathrm{kg}$. Schulz (2013) chose a range of 0.5 to 1.0 to 1.5 cents $/ \mathrm{kg}$ for the signing of a milk delivery contract. The profit in the present study corresponds to the (hypothetical) price premium in the aforementioned studies.

\section{Generation of Choice Sets}

The experimental design of the DCE with 2 generic alternatives and 5 attributes with $3 \times 3$ and $2 \times 4$ expressions gave a full factorial design of $[(3 \times 3 \times 3$ $\left.\times 4 \times 4)_{\text {Alternative } 1} \times(3 \times 3 \times 3 \times 4 \times 4)_{\text {Alternative } 2}\right]=$ 186,624 possible decision situations or choice sets. This design was too extensive to be practical and therefore had be reduced. The ORTOPLAN command was used to create an orthogonal reduced design of 16 choice sets in SPSS 25 (IBM Corp.). The D-efficiency value was $98.65 \%$, which is sufficiently close to a maximum value of $100 \%$ for perfect orthogonally balanced design (Kuhfeld et al., 1994).

To make the number of selection decisions manageable for survey participants, the sets were divided into 2 blocks of 8 selection situations each. Each selection 
decision included 2 alternatives and a status quo option for those who did not want to adopt the technology. Table 2 shows a typical choice set.

\section{Data Analysis}

The DCE method is based on the random utility theory, as first proposed by Thurstone (1927) and later adapted by McFadden (1986), McFadden and Train (2000), and Louviere et al. (2010a). Assuming utility maximization, each respondent chose the alternative that offered the greatest benefit. A farmer will, therefore, only decide to adopt if the perceived benefit is greater than the benefit of the status quo alternative. These utilities cannot be observed by the researcher but can be estimated by summarizing a vector of attributes associated with each choice alternative $\mathbf{X}$ and a vector of individual farm and farmer characteristics $\mathbf{Z}$. The conditional logit model, also known as McFadden's conditional logit (McFadden, 1974), is a widely used model for analyzing discrete choice data. This model assumes that the choice probability of existing alternatives is independent of the introduction of a new option. The so-called independence of irrelevant alternatives (IIA) can be tested using the Hausman test. In this case, the data are repeatedly analyzed using a conditional logit model, sequentially omitting one of the choice options. Significant outcomes in the Hausman test show that the omitted choice option is not independent of the other options. The IIA assumption is therefore violated, which, in turn, can lead to inconsistency in the estimation. For the data here, this was the case when omitting the second option $\left(\chi^{2}=55.56\right.$; $P=0.0000)$ and the status quo option $\left(\chi^{2}=35.40 ; P\right.$ $=0.0002)$. Omitting the first option did not violate the IIA assumption $\left(\chi^{2}=12.76 ; P=0.3093\right)$. The random parameter logit model (RPLM), also known as the mixed logit model, was therefore chosen. This model assumes that the functional form and the arguments of utility are common across respondents but that the parameters vary between individuals. Second, a latent class model (LCM) was estimated. The use of 2 complementary models enriches the analysis of preference heterogeneity by allowing a variety of information about behavior to be collected from one data set. The LCM resolved the IIA by assuming that people belong to different latent classes that have different preferences. The LCM allows parameter estimates to vary between different latent classes where preferences vary across the classes but are homogeneous within them (Boxall and Adamowicz, 2002; Greene and Hensher, 2003). To be able to quantify farmers' willingness to adopt on-farm concentration, the preferences of different groups within the sample need to be understood. Application of an LCM is useful here. Depending on the latent classes defined in the model, the participating farmers can be assigned to a class according to their individual characteristics and farm attributes. The general equations underlying the estimation process can be found in the Appendix.

\section{Modeling the Response Data}

Farmers' choices were analyzed with RPLM using the mixlogit command (Hole, 2007b) in Stata 16 (Stata Corp.) with 10,000 random Halton draws. In an RPLM model, the coefficients are assumed to be randomly distributed and to vary between farmers. It is also assumed that the estimated coefficients follow a normal distribution (Louviere et al., 2010b). The estimation contains an alternative specific constant (ASC) that measures the average benefit which, from the perspective of the data sample, is attributed to the adoption of raw milk concentration, without considering the specific requirements.

The coefficients are estimated using the maximum likelihood estimation technique. Based on the absolute magnitude of the estimated coefficients, no direct statements can be made about the influence of the explanatory variables ( $\mathbf{X}$ vector) on the choice decision. Therefore, WTP values can also be calculated using the estimated coefficients by calculating the ratio of the estimated marginal effects of a selection attribute to the estimated marginal effect of the profit offered.

Table 2. Example of a choice set

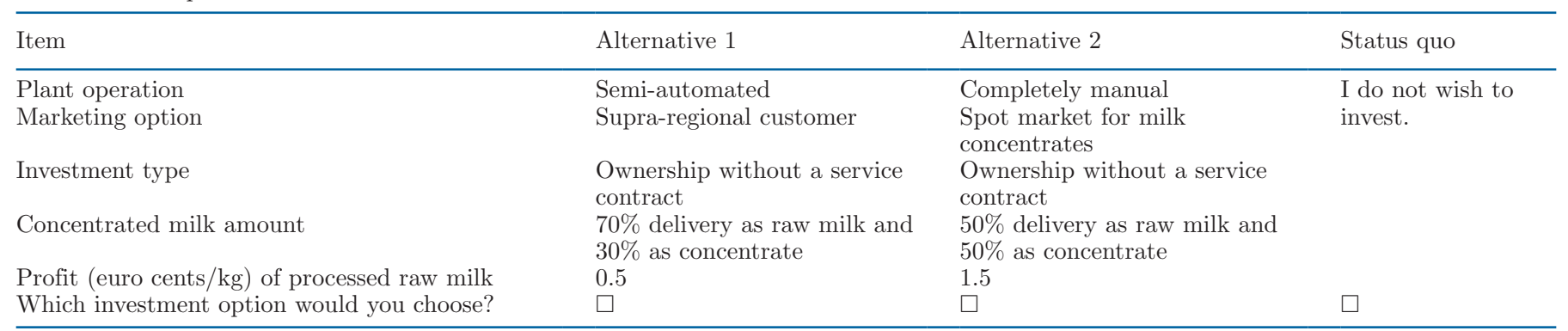


The LCM was based on the lclogit2 command in Stata 16 (Yoo, 2020). The optimal number of classes in the model has to be determined before estimation (Louviere et al., 2010b). For the decision on the number of classes, information criteria can be used for guidance. This study used the corrected Akaike information criterion, because it takes into account both the sample size and the size of the parameter space. Following the estimation of the model, the WTP of each class was calculated.

\section{RESULTS}

Survey answers from 116 farmers were obtained. Of these, 75 farmers were included in the evaluation, and 41 surveys were rejected due to missing answers. In this study, each questionnaire contained 8 choice sets. Because one participant completed only 7 choice tasks, a total of 599 choice sets could therefore be included in the estimation.

\section{Descriptive Statistics}

To document farmers' personal determinates, the questionnaire asked questions, for example, about onfarm milk production, herd size, farmers' age, contribution contracts, and economic parameters. Table 3 shows the descriptive statistics of the whole sample of surveyed farmers $(\mathrm{n}=75)$. The first third of the table shows all variables measured on an interval scale. The middle part shows all dummy-coded variables (i.e., yesno questions). The lower part of the table shows the categorical variables.

The average volume of milk produced per farm in the sample was $9,462 \mathrm{~kg}$ of milk per cow and year. This is higher than the average milk yield in Germany, which in 2017 amounted to 7,763 kg per cow and year according to the Federal Ministry of Food and Agriculture (2020). The average herd size of 186 cows per farm was also higher than the average total herd size of German dairy farms of 63.8 cows per farm in 2017 (Federal Statistical Office, 2020a). The mean age of the subjects in the sample was $32.1 \mathrm{yr}$, which is lower than the average age of German farmers of 53 (AgriDirect Deutschland GmbH, 2013).

Obviously, in the survey larger farms and younger managers were over-represented in comparison with official statistics. However, the official statistics tend to be dominated by a large number of very small dairy farms in southern Germany and partly in the southerly regions of eastern Germany. The German states of North Rhine-Westphalia and Rhineland-Palatinate made up $69.3 \%$ of the sample but actually comprise just $32.2 \%$ of all German dairy farms. In contrast, dairy cattle farms from the southern states (Bavaria and Baden-Württemberg) together account for $46.5 \%$ of the total number in Germany, whereas they contributed $22.7 \%$ to the sample (Federal Statistical Office, 2020b). Based on the descriptive statistics, it became clear that the sample is not fully representative of the population of German farmers according to official statistics. However, official statistics contain a relatively large number of small and part-time farms that account for only a relatively small share of total German milk output (Petersen and Hess, 2018). Consequently, the results of our study must be interpreted in terms of the actual personal determinates of the farmers; that is, larger farms owned by younger farmers producing higher milk yield than the German averages. However, the present sample composition placed greater emphasis on larger dairy farms in Germany. They are much more likely to continue operating over the next few years and therefore represent the unobservable population of dairy farmers who, in general, are still investing in their milk production.

The lower part of Table 3 lists discrete variables that make up vector $\mathbf{Z}$ in the estimation. In the present sample, $41.3 \%$ of the respondents delivered their milk to a private dairy and $56.0 \%$ to a cooperative dairy at a mean distance of $69.2 \mathrm{~km}$. There are 2.9 dairies within $50 \mathrm{~km}$ of their farm. In all, $82.7 \%$ of the survey respondents had a supply contract with a full delivery obligation with an acceptance guarantee, with a share of income from milk production of $73.6 \%$. Over the last 10 years, $40.0 \%$ of the surveyed dairy farmers had changed their dairy, and $36.0 \%$ had planned to change their dairy in the future. A total of $90.7 \%$ of the respondents in the sample were conventional, and $53.3 \%$ owned their respective companies. Other variables surveyed were the following: farm has a successor (53.3\%), participant has a higher education qualification either from a university or technical college $(80.0 \%)$, share of farms with small herd sizes $(9.3 \%)$, farmer has no access to loan finance $(2.7 \%)$, high risk $(53.3 \%)$ or lack of capital is an investment barrier (44.0\%), farmer has a lack of trustworthy information about milk processing technologies $(17.3 \%)$ or inexperience in making investment decisions $(9.3 \%)$.

\section{Random Parameter Logit Model Estimation}

The willingness to adopt on-farm concentration of raw milk was first investigated by estimating an RPLM. These results are shown in Table 4. To improve the fit of the model, only significant variables with a level of $10 \%$ or lower were retained in the subsequent estimation. After a Wald test $\left(\chi^{2}\right.$-value $=15.76 ;$ Prob $>\chi^{2}$ $=0.827), 22$ insignificant variables were removed from 
the RPLM. The McFadden pseudo $\mathrm{R}^{2}$ in the restricted RPLM was 0.135 . This was a sufficiently good model fit, as pseudo $R^{2}>0.200$ indicates an extremely good model fit (Louviere et al., 2010b). The WTP was then calculated in euro cents per kilogram for each explanatory variable. These results are shown in Table 5 .

In all, $78 \%$ of the 1,800 decisions were in favor of adopting an on-farm concentration plant. Of the total 75 participants, 35 always opted for on-farm concentration, and 7 always chose the status quo option. The overall probability of choosing alternatives 1 or 2 was 0.45 .

The estimated coefficients could be divided into the choice attributes $\mathbf{X}$, and the individual characteristics of respondents and their farms into the choice attributes $\mathbf{Z}$. For all variables of the choice attributes $\mathbf{X}$, the mean values of the respective distribution of an estimated coefficient are shown. The $P$-values refer to the standard deviation of the respective mean value. The reported $P$-values of these standard deviations pro-

Table 3. Descriptive statistics of survey respondents $(\mathrm{n}=75)$

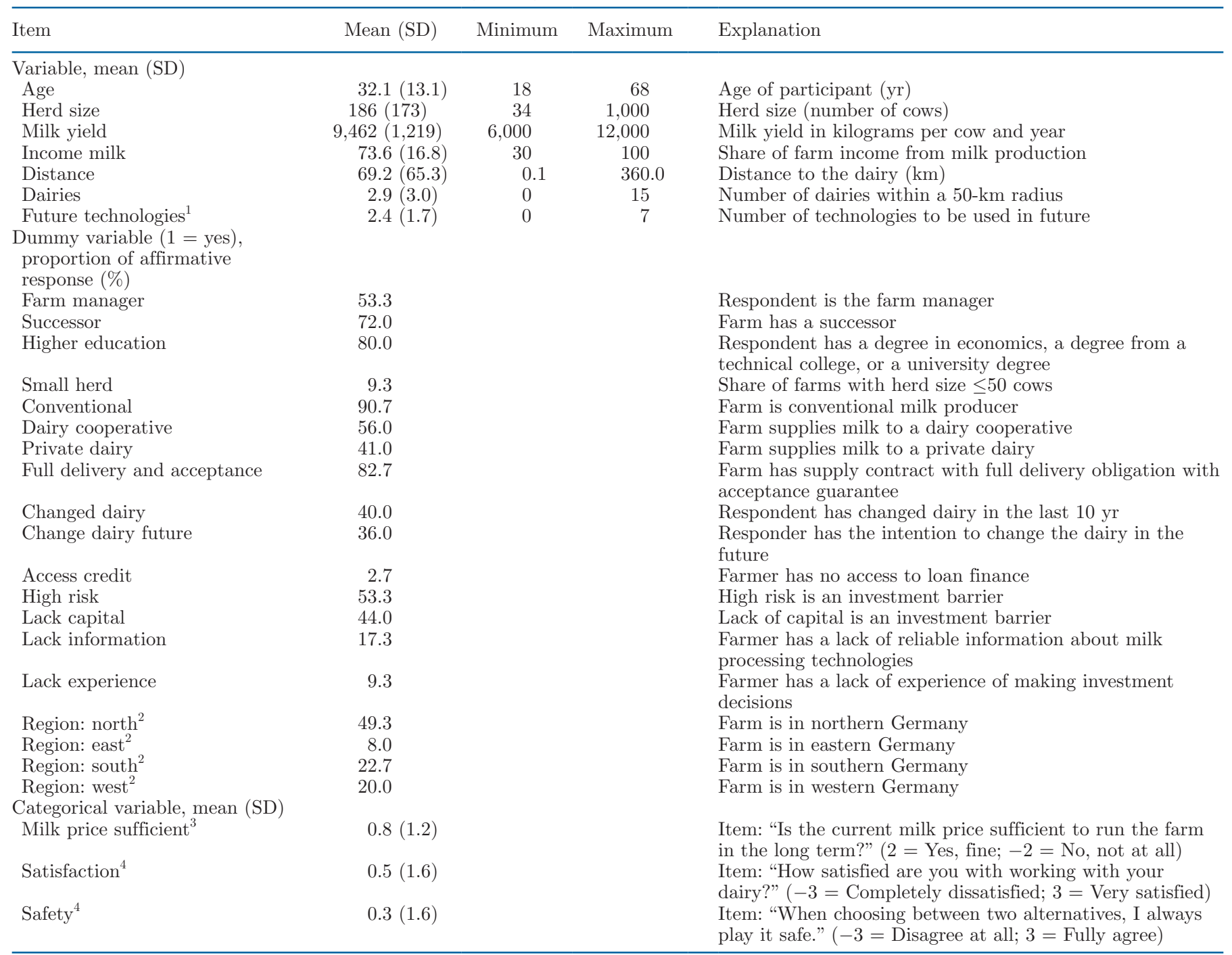

\footnotetext{
${ }^{1}$ There were 9 different technologies to choose from, including automatic milking systems, automatic sorting gates, and automatic mastitis detection tools. The variable is the sum of the technologies that are to be used in the next $10 \mathrm{yr}$ by each respondent.

${ }^{2}$ The distribution of the federal states is as follows: north (federal states: Lower Saxony, Schleswig-Holstein, Bremen, Hamburg), east (federal states: Brandenburg, Mecklenburg-Western Pomerania, Saxony, Saxony-Anhalt, Thuringia, Berlin), south (federal states: Baden-Wuerttemberg, Bavaria, Hesse), and west (federal states: North Rhine-Westphalia, Rhineland-Palatinate, Saarland).

${ }^{3}$ Four-point Likert scale, effect coded.

${ }^{4}$ Seven-point Likert scale, effect coded.
} 
Weissgerber and Hess: PREFERENCES FOR ON-FARM CONCENTRATION OF RAW MILK

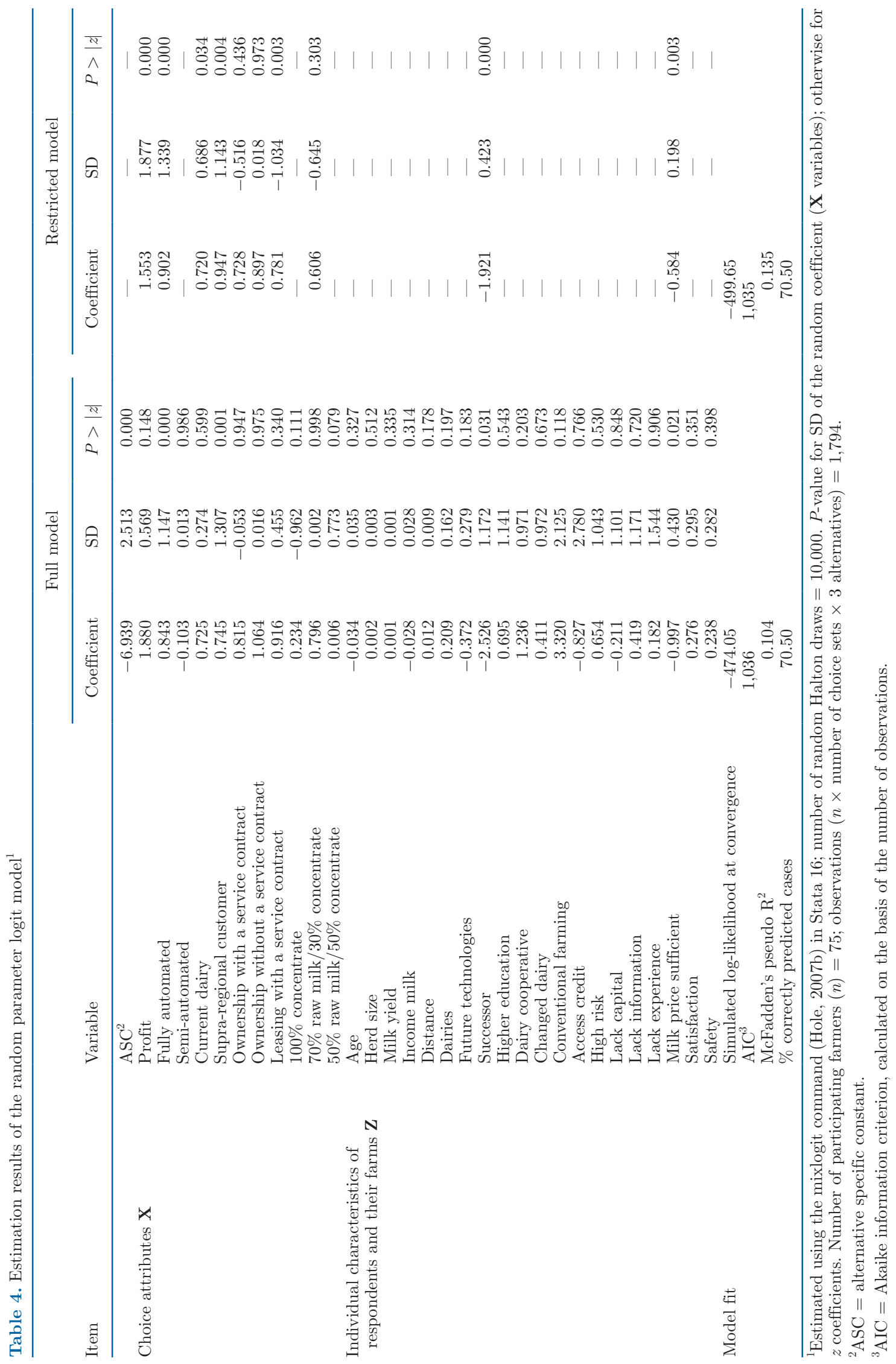


Table 5. Willingness to pay for significant variables of the program attributes $\mathbf{X}$ (restricted estimation)

\begin{tabular}{lccc}
\hline Variable & $\begin{array}{c}\mathrm{WTP}^{1} \\
(\text { cents } / \mathrm{kg})\end{array}$ & \multicolumn{2}{c}{$(2.5 \% / 97.5 \%)$} \\
\hline Fully automated & -0.581 & -1.062 & -0.266 \\
Current dairy & -0.464 & -0.882 & -0.195 \\
Supra-regional customer & -0.610 & -1.194 & -0.221 \\
$\begin{array}{l}\text { Ownership with a service } \\
\quad \text { contract }\end{array}$ & -0.469 & -1.023 & -0.090 \\
$\begin{array}{l}\text { Ownership without a service } \\
\quad \text { contract }\end{array}$ & -0.577 & -1.084 & -0.222 \\
Leasing with a service contract & -0.503 & -1.022 & -0.103 \\
$70 \%$ raw milk/30\% concentrate & -0.390 & -0.811 & -0.102 \\
\hline
\end{tabular}

${ }^{1} \mathrm{WTP}=$ willingness to pay, euro cents per kilogram of processed raw milk; calculated using the delta method.

vide information about a significance test in which the null hypothesis states that standard deviation equals zero and, consequently, that there is no heterogeneity of the estimated attribute. Thus, a rejection of the null hypothesis can be interpreted as the presence of heterogeneous preferences with respect to the particular choice attribute.

However, the significant standard deviation in the restricted RPLM revealed heterogeneity around the mean of the variables "profit," "fully automated," "current dairy," "supra-regional customer," and "leasing with a service contract." This indicates that preferences with respect to these variables vary widely between famers.

Adoption Versus Opt-Out. The ASC variable takes a value of 1 if an alternative is chosen and of 0 if a farmer chooses the opt-out alternative. It indicates a farmer's general preference to adopt an on-farm concentration plant. The ASC was not significant $(P$ $=0.137$ ), implying that no preferences for the "none" option were present, which could not be explained by variables included in the model.

Choice Attributes. The "profit" variable was highly significant $(P=0.000)$. Thus, the expected profit for the raw milk concentration plant increased the likelihood of adoption. The estimated coefficients for the "fully automated" attribute $(P=0.001)$ showed that a greater degree of automation was preferred over partial automation. In addition, the respondents would choose to supply the concentrate either to their "current dairy" $(P=0.000)$ or to a "supra-regional" customer $(P=$ 0.020). They preferred these options to marketing on the spot market. "Ownership without a service contract" $(P=0.002)$ had the greatest probability of being the chosen alternative, followed by ownership with a service contract $(P=0.013)$ and leasing with a service contract $(P=0.017)$. The marketing of concentrate was considered a supplement to the current marketing of raw milk. A proportion of about $30 \%$ concentrate was preferred to all other alternatives $(P=0.004)$.
Compared with the full estimation, the coefficients in the restricted estimation changed only slightly, confirming the models' robustness. If the size of the standard deviation was set in relation to the mean value of the coefficients in the RPLM, preferences for all the participants could be calculated as follows: $100 \times$ $\Phi\left(-b_{k} / s_{k}\right)$, where $\Phi$ is the cumulative standard normal distribution, and $b_{k}$ and $s_{k}$ are the mean and standard deviations, respectively, of the $k$ th coefficient (Hole, $2007 \mathrm{~b}$ ). Based on this, $25 \%$ preferred full automation, $14 \%$ preferred delivery to their current dairy, and $20 \%$ preferred delivery to a supra-regional customer. In the case of the investment type, $92 \%$ preferred ownership without a service contract, and the ownership relationship with a service contract was rejected outright. In all, $82 \%$ of the farmers preferred the delivery of $30 \%$ concentrate and $70 \%$ raw milk.

Socioeconomic Variables. In addition to the previously mentioned variables, the individual characteristics of the respondents and their farms, $\mathbf{Z}$ had an effect on the likelihood of adoption. A statistical significance was observed in the "milk price sufficient" and "successor" variables. Farms that regarded the current milk price as sufficient were obviously less willing to consider on-farm concentration of raw milk.

The models also showed that the respondents did not recognize any structural adoption barriers to on-farm concentration of raw milk. A subjective lack of experience in making investment decisions or a lack of capital did not seem to discourage selection of a statistically significant alternative.

The calculation of WTP for the individual attributes enabled a comparison of the results across different attributes. Consequently, Table 5 shows the calculated WTP for the respective attributes of a hypothetical adoption of on-farm concentration of raw milk based on the restricted estimation. The reported values were calculated from the estimated coefficients in Table 4. If an attribute offered the farmer high utility, this was rewarded with a correspondingly higher willingness to pay or, in this case, with a certain foregoing of profit, expressed by the negative sign in front of the WTP value.

It became clear that these milk producers would forego an average of 0.58 cents $/ \mathrm{kg}$ to operate a fully automated filtration system. This means that farmers would relinquish some of the profit for the time saving associated with full automation. In principle, the respondents would be willing to forego part of the profit for the various marketing options. For delivery to their previous dairy, the farmers would opt for less profit (0.46 cents $/ \mathrm{kg}$ ) than for delivery to a supra-regional customer $(0.61$ cents $/ \mathrm{kg})$. With the different types of investments, the participants would generally relinquish 
Table 6. Results from the latent class estimation ${ }^{1}$

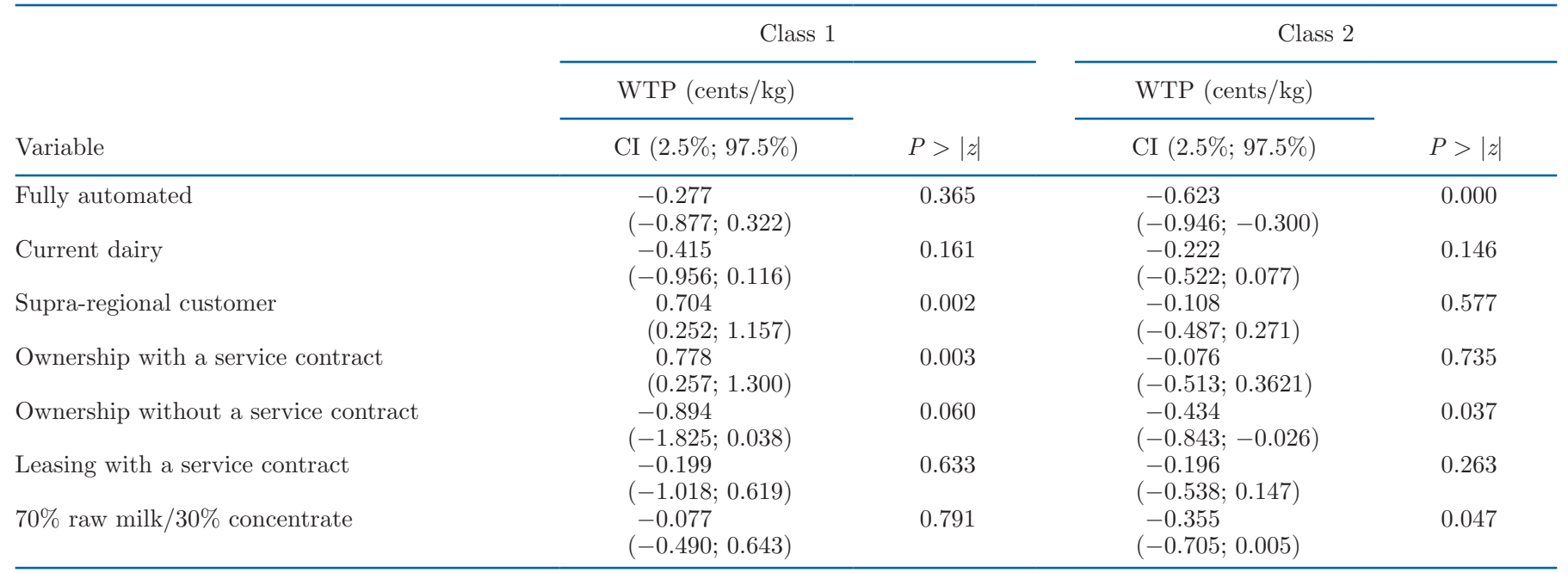

${ }^{1} \mathrm{WTP}=$ willingness to pay, euro cents per kilogram of processed raw milk. Average membership probability: class 1, 14.4\%; class $2,85.6 \%$.

some of the profit. At 0.58 cents $/ \mathrm{kg}$, the lowest value was for ownership without a service contract.

\section{Latent Class Estimation}

In addition to the RPLM, an LCM considers heterogeneous preferences among respondents. In the LCM each respondent is assumed to belong to a class, where preferences vary across, but not within, the classes. The optimal number of classes is determined ex ante, based on goodness-of-fit measures (Louviere et al., 2010b). For the model with 8 attributes and 2 membership variables, 2 classes revealed the best data fit, partly because of non-convergence issues with $>3$ latent classes. Table 6 presents the WTP results.

The average membership probability of class 1 was $14.4 \%$, and that of class 2 was $85.6 \%$. The average probability of choosing an alternative (weighted by the individual membership probability) in class 1 was $76.2 \%$ and in class $248.3 \%$. Therefore, we labeled the members in class 1 as "adopters" and the members in class 2 as "undecided."

The heterogeneity of preferences was reflected in different WTP estimates for the choice attributes. The "undecided" group relinquished some of the profit in return for a fully automated plant of their own with a service contract. The corresponding "fully automated" variable for the "adopters" was not significant, indicating that those who were willing to adopt the on-farm raw milk concentration equipment had no preferences in terms of plant operation. In addition, the "adopters" group requested a high premium for delivery to a supra-regional costumer and ownership with a service contract. A comparison between the latent class WTP results and those from RPLM showed similarities. This is evidence of the robustness of the estimation results.

\section{DISCUSSION}

Based on a sample of German dairy farmers, the present article investigated dairy farmers' willingness to have on-farm raw milk concentration equipment. A DCE was used to examine the possible barriers to adaptation and diffusion in the context of the future use of equipment for the separation of water from raw milk.

The appropriate sample size for DCE is still controversial (de Bekker-Grob et al., 2015). Although the sample in this study is rather small, it is comparable to sample sizes in other published literature. Schreiner and Hess (2017) used a sample of 78 when estimating farmers' willingness to accept a farm animal welfare program. Hensher et al. (2015) indicated that a sample size of 30 may be sufficiently large.

The first objective of this study was to investigate which characteristics of on-farm raw milk concentration equipment were important for German dairy farmers. Among all the attributes and their levels, full automation and delivery to the current dairy or to a supraregional customer were significant in the RPLM and therefore of importance for farmers. Additionally, out of the "investment type" attribute, ownership with or without a service contract and leasing with a service contract were significant in the RPLM. Furthermore, most farmers indicated that a proportion of $70 \%$ delivery as raw milk, and $30 \%$ processed on farm to concentrate, was most desirable.

When considering technology adoption, farmers' willingness to adopt also depends on economic factors, 
such as return on investment, total investment, and the system's performance (Borchers and Bewley, 2015). In the present estimation, "profit" was highly significant in both models, demonstrating that dairy farmers also take economic factors into account when considering on-farm concentration of their raw milk.

Furthermore, these results showed that ownership of the equipment without a service contract was the most preferred option, followed by leasing with a service contract. It is possible that ownership was favored because it reminded farmers of the existing investment type for their milking equipment. Another possible explanation could be that these farmers had a strong preference for autonomous possession and operation of the equipment, which was reflected in the rejection of a maintenance contract with the manufacturer. In addition, it should be borne in mind that the sample reflects the somewhat younger age, larger farm sizes, and perhaps more entrepreneurial than average attitudes of dairy farmers who may have tended to view the filtration technology as a rather straightforward filtration module that would be retrofitted to their milking parlor equipment. Ownership without a service contract was preferred despite the fact that the potential risk of technology failure can be reduced by providing dealer support (Sauer and Zilberman, 2012).

The strongest preference was for on-farm concentration as the second pillar, with $30 \%$ processed on the farm to concentrate and $70 \%$ delivered as customary raw milk.

As a consequence of the negative insignificant ASC, the farmers in this sample revealed, ceteris paribus, a general willingness to accept on-farm concentration of their raw milk compared with the opt-out option. Furthermore, it could be concluded that the listed attributes of the choice alternatives already adequately reflected the participants' preferences (Adamowicz et al., 1998; Meyerhoff and Liebe, 2009).

The second aim of this study was to establish how the sociodemographic characteristics of farmers and their farms influenced the probability of adoption. The results showed that farmers who deemed their current milk price to be sufficient were not interested in this technology. At the time of the survey, farmers were paid an average milk price of 36.6 cents $/ \mathrm{kg}$ (Federal Office for Agriculture and Food, 2019). Consequently, these farmers did not need a second pillar with raw milk concentration, because they could more than cover their costs with the milk price they were paid.

First, the negative sign of the significant coefficient for farms that had a farm successor was surprising. It should be noted that the sample of respondents had a much lower average age than the group of all farmers in Germany. Many of the younger participants were themselves successors to their parents' farms. These individuals were the ones most likely to face investment decisions for the farm. A reduced planning horizon until the farm is handed over to the successor could possibly be a potential barrier to adoption. However, the combined planning horizon of the current and future operators might be expected to have a positive effect on adoption of on-farm concentration. This finding was ambiguous for us.

In contrast to the findings reported by Key (2005), our survey did not identify a preference among the farmers to be independent of a dairy. Instead, the participating milk producers seemed to prefer close cooperation with their current dairy. Consequently, dairy cooperatives with relatively high milk collection costs in particular, as is the case for example in northeast Germany or Scandinavia, might be interested in introducing the appropriate technologies in cooperation with dairy farmers.

Furthermore, the "herd size" variable was found to have no effect on the adoption of an on-farm raw milk concentration plant, although Gargiulo et al. (2018) did establish that a larger number of cows increased the likelihood of technology adoption. Potential adoption barriers, such as a lack of experience with investments, too great a risk, or a lack of financing options, did not prevent farmers from choosing the alternative.

The latent class estimation also showed differences in farmers' preferences. Fewer than one-fifth were assigned to the adopter class. The remaining $85 \%$ were undecided about the possible adoption of on-farm raw milk concentration.

Further research should investigate the potential trade-off between risk aversion related to adoption of new technologies and the potential option of raising average profits from dairy farming. Moreover, by repeating the experiment at a later date and comparing it to our current results, future research could investigate whether farmers' decision-making behavior changes under different market conditions. Although the findings in this study provided a general understanding of the preferences for on-farm concentration technology, they should serve as a basis for further in-depth surveys conducted with a larger sample size to improve the informative value of the results. Furthermore, the preferences of milk processing dairies should be determined, as should the extent to which raw milk concentrate could be integrated into their existing processing procedures. That information would then be useful in the design of education, training, and service programs to support dairy farmers' adoption of on-farm membrane technologies for raw milk concentration. 


\section{CONCLUSIONS}

European dairy farmers are exposed to highly volatile raw milk prices and increasingly considering revenue diversification strategies as a means of reducing their financial risk. Although on-farm concentration of raw milk by membrane filtration could contribute to product diversification and resource conservation, it is not yet adopted by dairy farmers. This paper describes factors that may influence decisions by German dairy farmers to adopt on-farm concentration of raw milk: the key result was that the farmers preferred on-farm concentration as a second pillar with about $30 \%$ of concentrated raw milk. Willingness to adopt the new technology was further influenced by farm succession and perceived milk price risk. Particularly in regions with relatively high milk collection costs, on-farm concentration of raw milk may have economic potential. Dairy cooperatives with relatively high milk collection costs might, therefore, be interested in introducing appropriate technologies in cooperation with dairy farmers.

\section{ACKNOWLEDGMENTS}

The authors acknowledge the constructive comments from 3 reviewers and the editor. In addition, the participation and cooperation of the farmers during the collection of the data is acknowledged. We thank Sabine Gresch and Christian Zscherpe (University of Applied Sciences and Arts Hanover, Hanover, Germany), as well as Adriana Ackerschott and Freya Kuhlenkamp (Christian-Albrechts-Universität zu Kiel, Kiel, Germany) for their support in conducting the survey. The authors have not stated any conflicts of interest.

\section{REFERENCES}

Adamowicz, W., P. Boxall, M. Williams, and J. Louviere. 1998. Stated preference approaches for measuring passive use values: Choice experiments and contingent valuation. Am. J. Agric. Econ. 80:64-75. https://doi.org/10.2307/3180269.

Adesina, A., and J. Baidu-Forson. 1995. Farmers' perceptions and adoption of new agricultural technology: Evidence from analysis in Burkina Faso and Guinea, West Africa. Agric. Econ. 13:1-9. https: //doi.org/10.1111/j.1574-0862.1995.tb00366.x.

Adesina, A. A., and M. M. Zinnah. 1993. Technology characteristics, farmers' perceptions and adoption decisions: A tobit model application in Sierra Leone. Agric. Econ. 9:297-311. https://doi.org/10 .1111/j.1574-0862.1993.tb00276.x.

Adrian, A. M., S. H. Norwood, and P. L. Mask. 2005. Producers' perceptions and attitudes toward precision agriculture technologies. Comput. Electron. Agric. 48:256-271. https://doi.org/10.1016/j .compag.2005.04.004.

AgriDirect Deutschland GmbH. 2013. Jahresübersicht [Annual overview]. Accessed Mar. 10, 2019. https://issuu.com/agridirect/docs/ pressemitteilungen_2013.

Becker, K. M., R. L. Parsons, J. Kolodinsky, and G. N. Matiru. 2007. A cost and returns evaluation of alternative dairy products to determine capital investment and operational feasibility of a small- scale dairy processing facility. J. Dairy Sci. 90:2506-2516. https:// doi.org $/ 10.3168 /$ ids $2006-433$.

Borchers, M. R., and J. M. Bewley. 2015. An assessment of producer precision dairy farming technology use, prepurchase considerations, and usefulness. J. Dairy Sci. 98:4198-4205. https://doi .org $/ 10.3168 /$ jds.2014-8963.

Boxall, P. C., and W. L. Adamowicz. 2002. Understanding heterogeneous preferences in random utility models: A latent class approach. Environ. Resour. Econ. 23:421-446. https://doi.org/10 .1023/A:1021351721619.

Buningh. T. W. 1990. An economic evaluation of reserve osmosis for interregional milk transportation in Australia. In Australian Agricultural and Resource Economics Society. 1990 Conference (34th), Brisbane, Australia, Feb. 13-15. https://doi.org/https://doi.org/ 10.2204/AG.ECON.144921.

Chamberland, J., S. Benoit, A. Doyen, and Y. Pouliot. 2020. Integrating reverse osmosis to reduce water and energy consumption in dairy processing: A predictive analysis for Cheddar cheese manufacturing plants. J. Water Process Eng. 38:101606. https://doi .org/10.1016/j.jwpe.2020.101606.

Cox, G. C., and I. A. Langdon. 1985. Economic evaluation of reverse osmosis for reduction in milk transport costs. Aust. J. Dairy Technol. 40:113-117.

Danne, M., and O. Musshoff. 2017. Analysis of farmers' willingness to participate in pasture grazing programs: Results from a discrete choice experiment with German dairy farmers. J. Dairy Sci. 100:7569-7580. https://doi.org/10.3168/jds.2017-12756.

de Bekker-Grob, E. W., B. Donkers, M. F. Jonker, and E. A. Stolk. 2015. Sample size requirements for discrete-choice experiments in healthcare: A practical guide. Patient 8:373-384. https://doi.org/ 10.1007/s40271-015-0118-Z.

de Boer, R., and P. Nooy. 1980. Concentration of raw whole milk by reverse osmosis and its influence on fat globules. Desalination 35:201-211. https://doi.org/10.1016/S0011-9164(00)88611-7.

Dela Rue, B. T., C. R. Eastwood, J. P. Edwards, and S. Cuthbert. 2020. New Zealand dairy farmers preference investments in automation technology over decision-support technology. Anim. Prod. Sci. 60:133. https://doi.org/10.1071/AN18566.

Deutsche Forschungsgemeinschaft. 2019. Guidelines for safeguarding good research practice. Code of conduct. https://doi.org/10.5281/ ZENODO .3923601.

European Commission. 2021. EU Milk market observatory: Historical prices. Historical EU price serie of cow's raw milk. Accessed Oct. 6 , 2021. https://ec.europa.eu/info/food-farming-fisheries/farming/ facts-and-figures/markets/overviews/market-observatories/milk _en.

Feder, G., R. E. Just, and D. Zilberman. 1985. Adoption of agricultural innovations in developing countries: A survey. Econ. Dev Cult. Change 33:255-298. https://doi.org/10.1086/451461.

Feder, G., and D. L. Umali. 1993. The adoption of agricultural innovations. Technol. Forecast. Soc. Change 43:215-239. https://doi.org/ 10.1016/0040-1625(93)90053-A.

Federal Ministry of Food and Agriculture. 2020. Milchleistung je Kuh in Deutschland in den Jahren 1900 bis 2019 (in Kilogramm) [Milk yield per cow in Germany in the years 1900 to 2019 (in kilograms)] Accessed Dec. 29, 2020. https://de.statista.com/statistik/daten/ studie/153061/umfrage/durchschnittlicher-milchertrag-je-kuh-in -deutschland-seit-2000/.

Federal Office for Agriculture and Food. 2019. Preise für konventionelle und ökologisch/biologisch erzeugte Kuhmilch 2017/2018 [Prices for conventional and organic cow's milk 2017/2018]. Accessed Feb. 6, 2021. https://www.ble.de/SharedDocs/Downloads/DE/BZL/ Daten-Berichte/MilchUndMilcherzeugnisse/Milchpreise/Preise _KuhmilchKon-Bio2017.xlsx?_blob=publicationFile\&v=19.

Federal Office for Agriculture and Food. 2020. Verwendung von Milch in den Molkereien nach Kalenderjahren [Use of milk in dairies by calendar year]. Accessed Jun. 23, 2021. https://www .ble.de/SharedDocs/Downloads/DE/BZL/Daten-Berichte/ MilchUndMilcherzeugnisse/JaehrlicheErgebnisse/Deutschland/ Mengen/Verwendung_MilchInMolkereien.xlsx?__blob= publicationFile\&v $=4$. 
Federal Statistical Office. 2020a. Anzahl der Milchkühe je Betrieb in Deutschland in den Jahren 1995 bis 2020 [Number of dairy cows per farm in Germany in the years 1995 to 2020]. Accessed Dec. 29, 2020. https://de.statista.com/statistik/daten/studie/28755/ umfrage/anzahl-der-milchkuehe-je-halter-in-deutschland-seit $-1990 /$.

Federal Statistical Office. 2020b. Anzahl der Milchkühe pro Betrieb in Deutschland nach Bundesländern in den Jahren 2019 und 2020 [Number of dairy cows per farm in Germany by federal state in 2019 and 2020]. Accessed Dec. 29, 2020. https:// de.statista.com/statistik/daten/studie/382305/umfrage/betriebe -mit-milchkuhhaltung-in-deutschland-nach-bundeslaendern/.

Federal Statistical Office. 2021. GENESIS - German Official Statistics Portal. Database 41141-0004: Agricultural holdings with livestock farming, livestock: Germany, reference date, types of animals. Accessed Oct. 6, 2021. https://www-genesis.destatis.de/ genesis $/$ /online? operation $=$ table $\&$ code $=41141-0004 \&$ bypass $=$ true \&levelindex $=0$ \&levelid $=1643288689051$.

Fleming, A. M., and L. G. Hamm. 1988. An economic analysis of reverse osmosis filtration for interregional milk marketing. Agricultural Economics Report.

Garcia, A. III, and B. Medina. 1988. On-farm membrane concentration of milk. Trans. ASAE 31:274-278. https://doi.org/10.13031/ 2013.30699.

Gargiulo, J. I., C. R. Eastwood, S. C. Garcia, and N. A. Lyons. 2018. Dairy farmers with larger herd sizes adopt more precision dairy technologies. J. Dairy Sci. 101:5466-5473. https://doi.org/10 $.3168 /$ jds.2017-13324

Gebrezgabher, S. A., M. P. M. Meuwissen, G. Kruseman, D. Lakner, and A. G. J. M. Oude Lansink. 2015. Factors influencing adoption of manure separation technology in the Netherlands. J. Environ. Manage. 150:1-8. https://doi.org/10.1016/j.jenvman.2014.10.029.

German Federal Cartel Office. 2009. Sektoruntersuchung Milch: Zwischenbericht gemäß $§ 32$ e GWB - Dezember 2009 [Sector inquiry milk: Interim report pursuant to $\S 32 \mathrm{e}$ GWB-December 2009]. Accessed Jul. 22, 2020. https://www.bundeskartellamt.de/SharedDocs/ Publikation/DE/Sektoruntersuchungen/Sektoruntersuchung\%20 Milch\%20-\%20Zwischenbericht.html?nn=3591074.

Greene, W. H., and D. A. Hensher. 2003. A latent class model for discrete choice analysis: Contrasts with mixed logit. Transp. Res., Part B: Methodol. 37:681-698. https://doi.org/10.1016/S0191 -2615(02)00046-2.

Henning, D. R., R. J. Baer, A. N. Hassan, and R. Dave. 2006. Major advances in concentrated and dry milk products, cheese, and milk fat-based spreads. J. Dairy Sci. 89:1179-1188. https://doi.org/10 .3168/jds.S0022-0302(06)72187-7.

Hensher, D. A., and W. H. Greene. 2003. The mixed logit model: The state of practice. Transportation 30:133-176. https://doi.org/10 $.1023 / \mathrm{A}: 1022558715350$

Hensher, D. A., J. M. Rose, and W. H. Greene. 2015. Applied Choice Analysis. Cambridge University Press.

Hoehl, S., and S. Hess. 2021. Liquidity, hedging and the survival of North German dairy farms. Eur. Rev. Agric. Econ. jbab009. https: //doi.org/10.1093/erae/jbab009.

Hole, A. R. 2007a. A comparison of approaches to estimating confidence intervals for willingness to pay measures. Health Econ. 16:827-840. https://doi.org/10.1002/hec.1197.

Hole, A. R. 2007b. Fitting mixed logit models by using maximum simulated likelihood. Stata J. 7:388-401. https://doi.org/10.1177/ $1536867 X 0700700306$.

Just, R. E., and R. D. Pope. 2003. Agricultural risk analysis: Adequacy of models, data, and issues. Am. J. Agric. Econ. 85:1249-1256. https://doi.org/10.1111/j.0092-5853.2003.00538.x.

Kessler, H.-G. 2006. Lebensmittel- und Bioverfahrenstechnik: Molkereitechnologie [Food and bioprocess engineering: Dairy technology]. 4th rev. expanded ed., 1st reprint. Verl. A. Kessler.

Key, N. 2005. How much do farmers value their independence? Agric. Econ. 33:117-126. https://doi.org/10.1111/j.1574-0862.2005.00339 .x.
Krinsky, I., and A. L. Robb. 1986. On approximating the statistical properties of elasticities. Rev. Econ. Stat. 68:715-719. https://doi .org/10.2307/1924536.

Kuhfeld, W. F., R. D. Tobias, and M. Garratt. 1994. Efficient experimental design with marketing research applications. J. Mark. Res. 31:545-557. https://doi.org/10.1177/002224379403100408.

Kuhnert, H., and B. Wirthgen. 1996. Einzelbetriebliche Diversifikation durch hofeigene Lebensmittelverarbeitung und Direktvermarktung [ndividual farm diversification through on-farm food processing and direct marketing]. Pages 443-452 in Agrarstrukturentwicklungen und Agrarpolitik. 32. D. Kirschke, M. Odening, and G. Schade, ed. Landwirtschaftsverlag.

Landwirtschaftliche Rentenbank. 2020. Finanzierungsleitfaden: Informationen und Tipps zu Ihrem Agrarkredit [Financing guide: Information and tips on your agricultural loan]. Accessed Jul. 28, 2020. https://www.rentenbank.de/dokumente/Finanzierungsleitfaden .pdf.

Lauzin, A., Y. Pouliot, and M. Britten. 2020. Understanding the differences in cheese-making properties between reverse osmosis and ultrafiltration concentrates. J. Dairy Sci. 103:201-209. https://doi .org/10.3168/jds.2019-16542.

Louviere, J. J., T. N. Flynn, and R. T. Carson. 2010a. Discrete choice experiments are not conjoint analysis. J. Choice Modell. 3:57-72. https://doi.org/10.1016/S1755-5345(13)70014-9.

Louviere, J. J., D. A. Hensher, and J. D. Swait. 2010b. Stated Choice Methods: Analysis and Applications. Cambridge Univ. Press.

Luce, R. D. 1959. Individual Choice Behavior: A Theoretical Analysis. Wiley.

McFadden, D. 1974. Conditional logit analysis of qualitative choice behavior. Pages 105-142 in Frontiers in Econometrics. P. Zarembka, ed. Academic Press.

McFadden, D. 1986. The choice theory approach to market research. Mark. Sci. 5:275-297. https://doi.org/10.1287/mksc.5.4.275.

McFadden, D., and K. Train. 2000. Mixed MNL models for discrete response. J. Appl. Econ. 15:447-470. https://doi.org/10.1002/1099 -1255(200009/10) 15:5<447::AID-JAE570>3.0.CO:2-1.

Meyerhoff, J., and U. Liebe. 2009. Status quo effect in choice experiments: Empirical evidence on attitudes and choice task complexity. Land Econ. 85:515-528. https://doi.org/10.3368/le.85.3.515.

Nowak, P. J. 1987. The adoption of agricultural conservation technologies: Economic and diffusion explanations. Rural Sociol. 52:208220 .

Petersen, J., and S. Hess. 2018. The future of milk delivery relations from the perspective of German farmers. Ger. J. Agric. Econ. 67:80-94.

Ramírez, C. A., M. Patel, and K. Blok. 2006. From fluid milk to milk powder: Energy use and energy efficiency in the European dairy industry. Energy 31:1984-2004. https://doi.org/10.1016/j.energy 2005.10.014.

Robinson, R. K. 2011. Yogurt: Types and manufacture. Pages 525-528 in Encyclopedia of Dairy Sciences. J. W. Fuquay, ed. Academic Press.

Rogers, E. M. 1983. Diffusion of Innovations. 3rd ed. Free Press.

Rutten, C. J., W. Steeneveld, A. G. J. M. Oude Lansink, and H. Hogeveen. 2018. Delaying investments in sensor technology: The rationality of dairy farmers' investment decisions illustrated within the framework of real options theory. J. Dairy Sci. 101:7650-7660. https://doi.org/10.3168/jds.2017-13358.

Sauer, J., and D. Zilberman. 2012. Sequential technology implementation, network externalities, and risk: The case of automatic milking systems. Agric. Econ. 43:233-252. https://doi.org/10.1111/j .1574-0862.2012.00579.x.

Schiek, W. A., and E. M. Babb. 1989. Impact of reverse osmosis on southeast milk markets. J. Agric. Appl. Econ. 21:63-75. https:// doi.org/10.1017/S0081305200001187.

Schmitz, B., F. Duffort, and G. Satzger. 2016. Managing uncertainty in industrial full service contracts: Digital support for design and delivery. Pages 123-132 in Proc. 18th IEEE Conference on Business Informatics, Paris, France. IEEE. 
Schreiner, J. A., and S. Hess. 2017. The role of non-use values in dairy farmers' willingness to accept a farm animal welfare programme. J. Agric. Econ. 68:553-578. https://doi.org/10.1111/1477-9552 .12203 .

Schreiner, J. A., and U. Latacz-Lohmann. 2015. Farmers' valuation of incentives to produce genetically modified organism-free milk: Insights from a discrete choice experiment in Germany. J. Dairy Sci. 98:7498-7509. https://doi.org/10.3168/jds.2015-9515.

Schuck, P. 2011. Milk Powder: Types and Manufacture. Pages 108-116 in Encyclopedia of Dairy Sciences. J. W. Fuquay, ed. Academic Press.

Schulz, N. 2013. Discrete Choice Experimente zur Prognose des Entscheidungsverhaltens von Landwirten [Discrete choice experiments to predict farmers' decision behaviour]. $\mathrm{PhD}$ dissertation. Faculty of Agricultural and Nutritional Sciences, University of Kiel, Kiel, Germany.

Slack, A. W., C. H. Amundson, and C. G. Hill Jr.. 1982a. On-farm ultrafiltration of milk: Part 2-Economic analysis. Process Biochem. 17:23-33.

Slack, A. W., C. H. Amundson, C. G. Hill Jr., and N. A. Jorgensen. 1982b. On-farm ultrafiltration of Milk: Part 1-Technical feasibility studies. Process Biochem. 14:6,8-11.

Sørensen, I., S. Jensen, N. Ottosen, T. Neve, and L. Wiking. 2016. Chemical quality of raw milk retentate processed by ultra-filtration or reverse osmosis at the dairy farm. Int. J. Dairy Technol. 69:31-37. https://doi.org/10.1111/1471-0307.12296.

Sørensen, I., T. T. Le, L. B. Larsen, and L. Wiking. 2019. Rennet coagulation and calcium distribution of raw milk reverse osmosis retentate. Int. Dairy J. 95:71-77. https://doi.org/10.1016/j.idairyj .2019.03.010

Sørensen, I., T. Neve, N. Ottosen, L. B. Larsen, T. K. Dalsgaard, and L. Wiking. 2017. Storage stability of whole milk powder produced from raw milk reverse osmosis retentate. Dairy Sci. Technol. 96:873-886. https://doi.org/10.1007/s13594-016-0309-y.

Stabile, R. L. 1983. Economics of reverse osmosis and multistage evaporation for concentrating skim milk from 8.8 to $45 \%$ solids. J. Dairy Sci. 66:1765-1772. https://doi.org/10.3168/jds.S0022 $-0302(83) 82004-9$.

Sunding, D., and D. Zilberman. 2001. The agricultural innovation process: Research and technology adoption in a changing agricultural sector. Pages 207-261 in Handbook of Agricultural Economics: Volume 1, Part A: Agricultural Production. B. L. Gardner and G. C. Rausser, ed. Elsevier.

Thurstone, L. L. 1927. A law of comparative judgment. Psychol. Rev. 34:273-286. https://doi.org/10.1037/h0070288.

Trujillo-Barrera, A., J. M. E. Pennings, and D. Hofenk. 2016. Understanding producers' motives for adopting sustainable practices: The role of expected rewards, risk perception and risk tolerance. Eur. Rev. Agric. Econ. 43:359-382. https://doi.org/10.1093/erae/ jbv038.

Van De Gucht, T., W. Saeys, A. van Nuffel, L. Pluym, K. Piccart, L. Lauwers, J. Vangeyte, and S. van Weyenberg. 2017a. Farmers' preferences for automatic lameness-detection systems in dairy cattle. J. Dairy Sci. 100:5746-5757. https://doi.org/10.3168/jds .2016-12285.

Van De Gucht, T., S. van Weyenberg, A. van Nuffel, L. Lauwers, J. Vangeyte, and W. Saeys. 2017b. Supporting the development and adoption of automatic lameness detection systems in dairy cattle: Effect of system cost and performance on potential market shares. Animals (Basel) 7:77. https://doi.org/10.3390/ani7100077.

Vourch, M., B. Balannec, B. Chaufer, and G. Dorange. 2008. Treatment of dairy industry wastewater by reverse osmosis for water reuse. Desalination 219:190-202. https://doi.org/10.1016/j.desal 2007.05.013.

Wimmer, S., and J. Sauer. 2020. Diversification economies in dairy farming-Empirical evidence from Germany. Eur. Rev. Agric. Econ. 47:1338-1365. https://doi.org/10.1093/erae/jbaa001.

Winchell, E. H., and J. W. Hammond. 1984. An analysis of marketing cost impacts of reverse osmosis concentration of milk. Economic Report ER84-1, St. Paul, Minnesota. https://doi.org/10.2204/AG ECON.13077.
Yoo, H. I. 2020. lclogit2: An enhanced command to fit latent class conditional logit models. Stata J. 20:405-425. https://doi.org/10 $.1177 / 1536867$ X20931003.

Zall, R. R. 1984. Membrane processing of milk on the dairy farm. Food Technol. 38:88-91.

\section{ORCIDS}

Corinna Weissgerber (1) https://orcid.org/0000-0003-4042-2905 Sebastian Hess @ https://orcid.org/0000-0002-4597-7654

\section{APPENDIX}

\section{Econometric Analysis of the Discrete Choice Experiment}

In the discrete choice models, the utility $U$ over $j$ choice alternatives $(j=1, \ldots, J)$, for the choice $j^{*}$ in situation $t$ of $n$ individuals, can be described as follows:

$$
U_{n j * t}=\alpha_{C}+\boldsymbol{\beta}_{n} \mathbf{X}_{n j t}+\boldsymbol{\theta}_{j} \mathbf{Z}_{n}+\varepsilon_{n j t},
$$

where $\boldsymbol{\theta}_{j}$ forms a vector of fixed coefficients estimated for the vector $\mathbf{Z}$, which, in turn, contains variable-invariant explanatory variables. These variables represent, for example, the socioeconomic characteristics of the respondent, the size of the farm, or the average milk yield of the cows, as well as infrastructural features that give an indication of a farm's market situation, and could influence the farm's own raw milk concentration. The vector $\mathbf{X}_{n j t}$ contains the different types of choice alternatives. The vector $\boldsymbol{\beta}_{n}$ shows the coefficients estimated for the variables in vector $\mathbf{X}$. The ASC $\alpha_{C}$ captures the average impact of all nonobserved factors associated with the choice alternatives. In the present model, this constant is $\alpha_{C}=1$ if 1 of the 2 alternatives is selected, or $\alpha_{C}=0$ if the status quo option is selected.

We assumed that the error term $\varepsilon_{n j t}$ is independent and normally distributed. In contrast to the standard logit model, $\boldsymbol{\beta}$ could vary between farmers with the probability distribution $f\left(\boldsymbol{\beta}_{n} \mid \gamma\right)$ to account for respondents' heterogeneous preferences.

The probability $P$ that farmer $n$ selects the utilitymaximizing alternative $j^{*}$ from the available choice sets can be written as follows:

$$
\begin{aligned}
& P_{n j^{*} t}= \\
& \operatorname{prob}\left(\alpha_{C}+\boldsymbol{\beta}_{n} \mathbf{X}_{n j^{*} t}+\boldsymbol{\theta}_{j} Z_{n}+\varepsilon_{n j^{*} t}>\alpha_{C}+\boldsymbol{\beta}_{n} X_{n j t}+\boldsymbol{\theta}_{j} \mathbf{Z}_{n}+\varepsilon_{n j t}\right) \forall j * \\
& \neq j .
\end{aligned}
$$

All individuals were observed via a sequence of choices. It was assumed that the parameters estimated for each farmer were constant over the sequences. At the same 
time, this means that the preferences of an individual in the selection were different, but did not change in repeated choice situations. Because the individual $\beta_{n}$ are unknown, unconditional probability must be calculated as the integral of conditional probability over all possible values of $\boldsymbol{\beta}_{n}$ :

$$
P_{n j^{*} t}(\gamma)=\int P_{n j t}\left(\boldsymbol{\beta}_{n}\right) f\left(\boldsymbol{\beta}_{n} \mid \gamma\right) d \boldsymbol{\beta}_{n} .
$$

By estimating the parameters $\gamma$ describing the distribution of individual parameters (e.g., mean and covariance of the estimated coefficients), individual preferences can be described (Hensher and Greene, 2003). For a sequence of decisions, the probability of a decision by farmer $n$ is a product of the standard logits from each choice alternative.

The WTP values were calculated based on the delta method using the Krinsky and Robb (1986) parametric bootstrap for calculating the confidence intervals with 10,000 repetitions (Hole, 2007a):

$$
W T P_{n j} x_{n j}=\left(\frac{\sum_{n=1}^{N} \frac{\Delta p r o b_{j n}}{\Delta x_{j n}}}{N}\right) /\left(\frac{\sum_{n=1}^{N} \frac{\Delta p r o b}{p_{j n}}}{\Delta p_{j n}}\right) \cdot[4]
$$

The RPLM allows parameters to vary between farmers. In contrast, LCM assumes that the parameters vary between $C$ distinct classes. Class membership depends on the decision-maker's sociodemographic variables. The probability of farmer $n$ being in a particular class $c$ is given using the multinomial logit form:

$$
\operatorname{Prob}(c)=\frac{e^{\theta_{c} \mathbf{z}_{n}}}{1+\sum_{c=1}^{C-1} e^{\boldsymbol{\theta}_{c} \mathbf{z}_{n}}},
$$

where the vector $\mathbf{Z}_{n}$ contains the farm and farmers' socioeconomic characteristics, and $\boldsymbol{\theta}_{c}$ is a vector of class-specific coefficient parameters for the membership variables in $\mathbf{Z}$, with the last class normalized to zero as the reference segment. The $\boldsymbol{\theta}$ coefficients indicate whether the given membership variable increases or decreases the probability of an individual belonging to a class. 